\title{
Negar a leitura literária hoje pra conter a organização política amanhã: formação estética
}

para quem?

\author{
Denying literature reading today to contain the \\ political organization tomorrow: who is the aesthetic
} formation for?

Negar la lectura literaria hoy para contener la organización politica mañana: ¿formación estética para quién?

PRISCILA MONTEIRO CHAVES

ANDRESSA DIAS KOEHLER (D) b

\section{Resumo}

Este ensaio discute pressupostos psicológicos e filosóficos para a formação estética da criança na experiência com a leitura de literatura. Nesse viés, problematiza brevemente políticas de acesso à leitura promovidas pelo Ministério da Educação; trata da imaginação e da criatividade, na perspectiva vygotskyana, como atividade humana determinada pela cultura e pela linguagem; e dos conceitos de imagem dialética e de mímesis, sob a perspectiva de Walter Benjamin, concebendo a leitura literária contrária à instrução de conteúdo moral, informativo, de simples divertimento, de caráter didático para o ensino da língua ou, ainda, de interpretação livre e espontânea por parte da criança. Esse esforço empenhado se justifica pela necessidade de que seja ainda discutida a dimensão estética da leitura literária

\footnotetext{
a Universidade Federal do Espírito Santo, Vitória, ES, Brasil. Doutora em Educação, e-mail: priscila.chaves@unoesc.edu.br

b Universidade Federal do Espírito Santo, Vitória, ES, Brasil. Doutora em Educação, e-mail: andressak@gmail.com
} 
infantil como um caminho para que as crianças acessem seus sentimentos mais conflitantes, extrapolem fronteiras de condutas padronizadas, participem da cultura, atribuam sentidos ao vivenciado, desenvolvam a atividade criadora e conciliem maneiras de se relacionar com o mundo. Isso está estreitamente vinculado a uma perspectiva de formação que não se ajusta à moral do trabalho que propõe ideias conciliadoras, pragmáticas e utilitárias que promovem a contenção política - , mas à necessidade de formar-se, de modo mais pleno possível, como um sujeito do conhecimento histórico desde a infância.

Palavras-chave: Literatura Infantil. Imaginação. Contenção política. Formação estética. Condução moral.

\begin{abstract}
This essay discusses psychological and philosophical assumptions for the aesthetic formation of the child along the literature reading experience. In this bias, briefly problematizes policies of access to reading promoted by the Ministry of Education; deals with imagination and creativity, through a Vygotskyan perspective, as human activity determined by culture and language; and the concepts of dialectical image and mimesis, according to Walter Benjamin, conceiving literary reading contrary to the instruction of moral content, informative, of simple fun, of didactic character for language teaching or, even, of free and spontaneous interpretation by the child. This effort is justified by the need to discuss the aesthetic dimension of children's literary reading as a way for them to access their most conflicting feelings, to excel the boundaries of standardized conduct, to participate in culture, to make the experience meaningful, develop creative activity and conciliate ways of relating to the world. This is closely linked to a perspective of formation that does not fit work moral - which proposes conciliatory, pragmatic and utilitarian ideas that promote political restraint -, but to the need to train, as fully as possible, as a subject of historical knowledge since childhood.
\end{abstract}

Keywords: Children's Literature. Imagination. Political restraint. Aesthetic training. Moral driving.

\title{
Resumen
}

Este ensayo analiza los supuestos psicológicos y filosóficos para la formación estética del niño en la experiencia de leer literatura. Problematiza brevemente las políticas de acceso a la lectura impulsadas por el Ministerio de Educación; se trata de la imaginación y la creatividad, en la perspectiva vygotskiana, como una actividad humana determinada por la cultura y el lenguaje; y los conceptos de imagen dialéctica y mimesis, desde la perspectiva de Walter Benjamin, entendiendo la lectura literaria contraria a la instrucción de contenido moral, informativo, de simple diversión, de carácter didáctico para la enseñanza de la lengua o, aún, de libre interpretación y espontáneo por el niño. Este esfuerzo se justifica por la necesidad de seguir discutiendo la dimensión estética de 
la lectura literaria infantil como una forma para que los niños se den cuenta de sus sentimientos más conflictivos, traspasen los límites de las conductas normalizadas, participen de la cultura, asignen significados a la experiencia, desarrollen la actividad de creación y concilien formas de relacionarse con el mundo. Esto está íntimamente ligado a una perspectiva de formación que no se ajusta a la moral del trabajo - que propone ideas conciliadoras, pragmáticas y utilitarias que promueven la moderación política-, pero la necesidad de formarse, en la mayor medida posible, como sujeto del conocimiento histórico desde la infancia.

Palabras clave: Literatura infantil. Imaginación. Contención política. Formación estética. Conducta moral.

\section{Introdução}

Estamos publicando este texto em tempos que não têm nos permitido arredar os pés e a cabeça dos rumos a que a educação pública vem sendo conduzida. Além das antigas investidas do capital no amestramento docente para a diminuição dos conflitos provenientes das relações de exploração capital e trabalho (DECKER; EVANGELISTA, 2019) e no sequestro da memória das crianças acirrado pela indústria do entretenimento (STEN, 2020), vivemos um ataque sanitário que conglomera a existência de um vírus letal e a negligência no seu controle em nome de uma economia que não pode parar. Para que a gente não sinta a perversidade de tudo isso, dentre os rumos do capital que forma o formador (MÉSZÁROS, 2008) encontra-se em emergência o desenvolvimento de competências socioemocionais, estratégia de contenção política que esfacela ainda mais nossas possibilidades de formação humana (CHAVES; EVANGELISTA, 2020). Não deixemos de pontuar também o retorno a galope dos expedientes de moralização promovidos pelo Governo Bolsonaro, que tem deixado sua marca ideológica inscrita no interior da Política Nacional de Alfabetização (BRASIL, 2019a).

É nesse panorama mais alargado e estruturante que este ensaio se inscreve. Discutimos alguns fundamentos psicológicos e filosóficos da formação estética da criança, para que se reafirme a necessidade de oposição ao que vem sendo proposto para a leitura literária infantil. Fazemos coro com a tentativa (ainda) de superação da sua compreensão seja como criação meramente espontânea de sentido, seja como forma de moralização, como simples divertimento ou como meio de instrumentalizar o ensino da língua materna. 
Antes de relacionarmos os referidos fundamentos à literatura infantil, apresentamos, muito brevemente, algumas políticas públicas para o campo nos últimos anos. É bem verdade que os conceitos debatidos nos ajudam a melhor entender parte do sentido de tais propostas. Contudo, é importante pontuar que não se trata de um movimento analítico rigoroso de nenhuma delas, visto que não há aqui a tarefa exegética de nos debruçarmos sobre qualquer uma das propostas arroladas na referida seção, apontando determinações e investigando porquês.

Pensar a leitura literária na infância implica trazer à luz determinados elementos que aparecem no inventário de antigos e recentes engodos que a condicionam. O mais convencional deles é correntemente recuperado na sua constituição histórica por autores que se destinam a contribuir com a área ou que produziram obras artísticas literárias. Cecília Meireles, por exemplo, resistia à ideia de que haveria uma literatura infantil: "Tudo é uma Literatura só. A dificuldade está em delimitar o que se considera como especialmente do âmbito infantil" (1979, p. 19). Para a autora, livros escritos "para crianças" e que tivessem como função principal o ensino não deveriam ser considerados literatura infantil. Essa, por sua vez, deveria privilegiar a apreciação estética em detrimento do ensino. O que nos provoca pensar como o mercado robustece essa adjetivação e se essa escolha é mais determinada por sua produção, processo editorial ou por sua recepção. ${ }^{1}$

Desde logo, a produção e a "aplicação" de textos literários infantis com fins didáticos são produtos de uma construção histórica da infância que as próprias ciências humanas tentam traçar: a noção de adulto em miniatura, na Idade Média; as aulas em lugares públicos juntamente com adultos, no Renascimento; o surgimento, no século XVII, das quarentenas em escolas divididas por turmas ou séries; as

\footnotetext{
1 Além dos conflitos sobre o que caracteriza a literatura infantil como tal, Dalvi (2019) sintetizou em outros quatro tópicos questões lançadas pela comunidade científica sobre o tema: "I. A literatura infantil é mesmo literatura? [...] Se 'não pode' lançar mão de todos os recursos à disposição do criador [...] é, de fato, um objeto que incida contra a doxa da mesma monta de outras manifestações culturais? [...] II. Pode-se falar em Literatura Infantil ou deve-se falar em livro para a criança? [...] IV. O estudo dessa produção e das relações de que participa compete, fundamentalmente, a que campo: Pedagogia ou Letras? Outro? [...] V. O que é que adjetiva uma literatura: sua origem ou fronteira geográfica (p. ex., Literatura Brasileira), a etnicidade de seu produtor (p. ex., Literatura Negra), seu estilo ou pertencimento geracional (p. ex., Literatura Barroca ou Marginal) ou, enfim, sua destinação (p. ex., Literatura Infantil)" (2019, p. 149-150)?
} 
associações religiosas de crianças a anjos, sinônimo de inocência e pureza divina; a prática da catequese com o ensino por textos religiosos; o reconhecimento, no final do século XVII, da fragilidade da infância. Se antes essa era considerada uma fase de incompletude e deformação em relação ao adulto, a partir do século XVII começa a ascender uma certa importância ao ser e estar no mundo como criança.

Avançando nesses paradigmas, é ainda mais importante lembrar que foi em meio à individualização provocada pelo progresso das forças produtivas que as infâncias foram mostrando os antagonismos enraizados na estratificação social: "A criança proletária [nascia] dentro de sua classe. Mais exatamente, dentro da prole de sua classe, e não no seio da família” (BENJAMIN, 2002, p. 122). Desde sua gestação, ela era parte da prole. Proteger seus herdeiros era tarefa da família burguesa que criava a necessidade de ensinar a ser cidadão no interior da lógica da propriedade privada. Já “a família proletária não [era] para a criança melhor proteção contra uma compreensão cortante da vida social do que o seu puído casaquinho de verão contra o cortante vento de inverno" (BENJAMIN, 2002, p. 122). Existir nessa realidade a direcionava "no sentido de aguçar desde cedo, na escola da necessidade e do sofrimento, sua consciência (2002, p. 122). Para Benjamin, essa era a semente de sua consciência de classe.

Em um escrito de 2016, publicado em 2018, aviventamos a centelha do debate sobre o confronto entre o ato de se desassossegar com a experiência estética realizada no contato com a leitura de literatura e a "[...] tentativa de ensinamentos de princípios morais [...] como têm preconizado os modelos formativos contemporâneos e os manuais que insistem em utilizar a literatura infantil [...] para fins instrumentais" (GHIGGI; CHAVES; SCHNEIDER, 2018, p. 444). Discussão essa que há algumas décadas vem sendo reincidente, seja por aqueles que estudam a infância, seja por aqueles que estudam literatura, ou estética, de maneira mais ampliada. O fato é que o aumento dos canais de controle da formação intelectual da criança — bem como a tentativa de manipulação de suas emoções — parece ser atualizado em diferentes formas de expressão, mas seu princípio fundamental permanece. Zilberman (1985), por exemplo, sintetizou o processo histórico que indica o envolvimento da criação da Literatura Infantil e as reformas da instituição escolar com essa missão. Lembremos do quanto o discurso da sociedade burguesa em defesa da cidadania necessitou, 
juntamente com a escola, com a igreja e com as famílias, de um cooperário que atuasse pela ludicidade, encontrando no livro infantil um braço forte pra essa tarefa.

Antonio Candido caracterizou a literatura como um bem incompressível às civilizações para a promoção de uma integridade espiritual, tão importante quanto os demais elementos que asseguram a sobrevivência física em níveis decentes, como "[...] a alimentação, a moradia, o vestuário, a instrução, a saúde, a liberdade individual, o amparo da justiça pública, a resistência à opressão etc.” (2004, p. 174). Ele ainda assinala que os critérios de incompressibilidade variam conforme a organização social, pois apenas uma organização justa atentaria às necessidades profundas do ser humano que, quando não satisfeitas, causariam desde desorganizações pessoais a frustrações mutiladoras. O autor sustenta que a literatura, assim como o sonho, transporta o ser humano ao universo fabulado. E é nessa vigília que nasce a ficção e a poesia, presentes "[...] em cada um de nós, analfabeto ou erudito — como anedota, causo, história em quadrinhos, noticiário policial, canção popular, moda de viola, samba carnavalesco" (2004, p. 174-175). Assim sendo, uma sociedade regida por uma racionalidade técnica, tão criticada pela escola de Frankfurt por sua consequente condução à barbárie, custosamente compreenderia a arte e a literatura como bens incompressíveis aos seres humanos, designando a essas a ocupação didática de compor os currículos escolares com outros fins.

Na década de 1980, Silva (1991) denunciava que ainda havia dificuldades em se compreender a leitura literária como prazer estético e que tal potencialidade seria mais exonerada quando a leitura entra na instituição escolar. ${ }^{2}$ Segundo ele, o prazer e o desejo cediam lugar ao autoritarismo da imposição, do tempo pré-estabelecido para os momentos de leitura, das leituras pré-estabelecidas, e outros meios que vão acarretando o desgosto pela leitura e, consequentemente, a ausência cada vez maior de leitores (SILVA, 1991). Nos últimos anos, esse autoritarismo perdeu espaço não para uma práxis comprometida teórica, política e filosoficamente com a formação humana, mas para uma concepção descompromissada e imediatista de prazer. Basta

\footnotetext{
${ }^{2}$ Afirmação que deve ser lida com muita cautela, uma vez que a escola é o espaço privilegiado não somente de uma mediação literária mais qualificada e sistematizada, mas de participação na cultura quando se trata de ler os conflitos sociais com as bases que a literatura nos dá.
} 
olhar para os modos como ela é prescrita na Base Nacional Comum Curricular (BRASIL, 2018) ou para a forma como a famigerada leitura deleite entra na escola que, bastante propagada pelas políticas públicas de formação continuada de professores da educação básica, esvaziou muitos de seus fundamentos estruturantes, tratando-a ainda mais como distração ou mero divertimento.

No que compete aos seus rumos na educação pública brasileira, não é suficiente lembrar que a literatura infantil historicamente atendeu a uma demanda " $\mathrm{da}$ própria estrutura da cultura ocidental em relação a seu tradicional conceito de ser infantil" (PALO; OLIVEIRA, 2006, p. 8) - como ser desprovido de autoridade, aquele que não tem o poder da fala (in-fans) e que a ele precisa ser dito o que fazer e o que pensar. Não explicitamos essa trama aqui, mas advertimos a necessidade de que seja levada em consideração nessa conversa a posição de subalternidade nas relações capitalistas dependentes de produção, às quais estamos submetidos e das quais deriva nossa subserviência quanto ao que deve ser ensinado nas escolas (BRASIL, 2018) e quanto às avaliações em larga escala que geram um valioso produto a ser mercadejado no balcão de negócios dos acordos internacionais (NEVES; PICCININI, 2018).

\section{Conta pra mim e outras políticas públicas}

Se (mal) compreendido o conceito de políticas públicas de modo mais delimitado e restritivo, como a materialização das ações do Estado, pelas formulações de ações legais mais diretivas ou em curso, é, conforme manifestou Paiva (UFMG, 2014), problemático falar da existência de políticas públicas de leitura no Brasil, uma vez que se constatam ações bastante circunscritas a práticas livrescas de distribuição de material e oferta de cursos de curta duração, pautados pelo utilitarismo, no âmbito dos estados e municípios da rede pública. Desse modo, até mesmo dentro de uma concepção burguesa, neoliberal e legalista de Estado, as ações já desenvolvidas nos últimos anos pouco vêm configurando como políticas culturais e, principalmente, educacionais, que apontem, de modo mais efetivo, um modelo de sociedade a ser claramente percebido pelas ações do Estado. A própria ausência delas resta determinante para nossa compreensão dessa concepção de sociedade que vem sendo içada. 
Isto é, no que compete ao ato de ler, à formação de leitores e, sobretudo, à leitura literária, já era frágil a ideia de um sistema organizado que configurasse um ramo de uma ideação mais global. No que compete ao atual governo, parece que essas ações estão ainda mais impraticáveis, a considerarmos o que propôs a Política Nacional de Alfabetização (PNA), instituída pelo Decreto no 9.765, de 11 de abril de 2019 (BRASIL, 2019a), criada pela Secretaria de Alfabetização do Ministério da Educação (MEC). Esse ato regulamentou programas e ações fundamentados em "evidências científicas" nacionais e internacionais. Dentre eles está o Conta pra mimGuia de Literacia Familiar (BRASIL, 2019b), no qual as crianças, desde a idade da Educação Infantil, são público-alvo. Ainda que os comerciais veiculados em horário nobre nos canais de TV aberta sugiram certo prestígio das obras literárias, o documento inicial não apresentava menção substantiva a elas e a proposta, até pouco tempo, essencialmente não passava de uma tentativa de antecipação da alfabetização. A proposta instrui práticas para as crianças nessa fase por considerá-la momento estratégico de preparação para as competências da área de linguagens dos anos iniciais do Ensino Fundamental (BRASIL, 2018).

Nos últimos meses, fomos surpreendidos ${ }^{3}$ por uma coleção de quarenta livros parte do Conta Pra Mim. Trata-se de adaptações ${ }^{4}$ bastante reduzidas $^{5}$ de fábulas e contos de fadas clássicos, com ilustrações falseadas, bastante caricaturescas e absolutamente comerciais. As histórias foram significativamente modificadas, edição essa que as tornou simplórias principalmente pelo empobrecimento que sofre a

\footnotetext{
${ }^{3} \mathrm{Na}$ verdade, o uso da expressão, lamentavelmente, é retórico, uma vez que: 1) as medidas de retrocesso com a educação básica e superior são sistematicamente apresentadas a nós pelo Governo Bolsonaro; 2) a PNA prevê, como uma de suas diretrizes, uma certa proposta de educação literária no interior da qual o programa nasce; 3) a PNA (BRASIL, 2019c, p. 45) já havia nos antecipado que um dos seus pilares não era fazer um investimento no que concerne ao acesso àquilo que existe como acúmulo cultural brasileiro e clássicos estrangeiros. Em seu inciso XI, Art. $8^{\circ}$, o documento arrolou como ações de implementação o "incentivo à produção e à edição de livros de literatura para diferentes níveis de literacia" (grifos nossos). Isso também nos foi avisado!

${ }^{4}$ Disponível em: http://alfabetizacao.mec.gov.br/contapramim. Acesso em: 22 set. 2020.

${ }^{5} \mathrm{~A}$ "leveza" que é conferida aos textos parece ter sido atendida por Marismar Borém, editora dos livros, "[...] fonoaudióloga de formação e dona de uma editora de Belo Horizonte chamada Cora, pouco conhecida no cenário nacional do mercado editorial. Em seu site na internet, a editora se propõe a publicar obras 'que ensinem coisas boas para as famílias e que levem bons exemplos para a infância', com histórias 'construtivas, alegres, sadias, com estímulos positivos que despertam o pensar e o sentir de nossas crianças"' (VALENTE, 2020).
} 
linguagem. Dentre os quarenta livros, não há indígenas como protagonistas e, no que compete às personagens negras, quando aparecem (em apenas 10\% delas), são ilustrações de "pessoas brancas apenas pintadas de marrom" (VALENTE, 2020). Os livros não creditam as histórias originais e tiveram a supervisão técnica do secretário de alfabetização do MEC, Carlos Francisco Nadalim ${ }^{6}$. Ricardo Valente (2020) entrevistou Rosana Mont'Alverne, cuja autoria é registrada em três livros ${ }^{7}$. Entretanto, a "autora" declara:

"Quando sou eu a editora, eu troco ideias com os autores e chegamos a um denominador comum quanto à publicação. Como autora de três textos, como nesse caso da coleção Conta Pra Mim, a edição fugiu ao meu alcance e algumas alterações foram feitas". Em síntese, a autora não reconhece como seu o resultado final das adaptações.

A deturpação das histórias narradas priva as crianças de experiências simbólicas extremamente ricas, necessárias ao processo de formação, pois remove grande parte dos confrontos de natureza humana (medos, angústias, desejos). Nos livros destinados às crianças, é possível perceber a intencionalidade de uma forma específica e concreta de relação. Desse modo, o material ora falseado não manifesta somente uma noção de infância e uma forma de se relacionar com ela. Afora isso, “exprime materialmente uma forma de vida. Quer dizer, é a partir da particularização e da especificidade da relação educativa que [ele] se conecta com a totalidade, nessa identidade de formas sociais" (CATINI, 2013, p. 162). Não podemos deixar de afirmar que isso anda junto com um projeto de Estado que orquestra, simultaneamente, instrumentalizar e formatar as futuras massas trabalhadoras para determinados tipos de funções subalternas (condizentes com a posição que ocupam nas relações capitalistas internacionais de dependência) e, na medida do possível, ressequir as possíveis raízes de futuras lideranças políticas das lutas que emergiriam exatamente lá, onde mais se necessita que elas emerjam (FONTES, 2018).

\footnotetext{
${ }^{6}$ Ex-aluno de Olavo de Carvalho, figura entre os ultraconservadores que apoiam Jair Bolsonaro. É autor do e-book As 5 Etapas para Alfabetizar seus Filhos em Casa - o Guia Definitivo, criador do blog Como Educar Seus Filhos. Nadalim ficou conhecido, principalmente, por defender o método fônico.

7 São eles: A lenda da vitória-régia, Chapeuzinho vermelho e João e Maria.
} 
Necessário também lembrar que a prioridade de atendimento do programa são as famílias que se encontram em "vulnerabilidade socioeconômica" 8 (BRASIL, 2019b) ${ }^{9}$. Dessa forma, àqueles que já são negadas condições de melhor compreender a complexidade do universo imediato no que compete, sobretudo, à educação escolarizada, resta ofertado um atrofiamento da capacidade imaginativa e maior restrição do contato com materiais prenhes de linguagem verbal e não verbal que poderiam favorecer uma reelaboração dos modos de se apropriar da realidade material.

Segundo a teoria bakhtiniana (2011), a palavra do outro não é mera informação, conjunto de regras, modelos; ela busca estabelecer o próprio firmamento dos nossos modos de ser no mundo. Sendo a linguagem uma instância que integra comunidades locutoras, sem exclusão daquelas que objetivamente encontram-se em oposição política, subjetivamente, é construída nessa relação interativa um falso caráter supra-histórico do signo linguístico, que, em aparência, não teria datação de sua gênese nem condicionantes sociais. Isso faz com que nossa percepção se distancie inclusive do fato de que os processos de entendimento e de apropriação das palavras alheias corporificam as determinações da nossa consciência. Portanto, é a luta de classes acontecendo na linguagem, em uma ofensiva à sensibilidade, mostrando que espécie de relação social é alavancada desde a infância.

Trata-se, nitidamente, de uma estratégia de contenção política que opera, aos moldes da lógica capitalista, pela antecipação do futuro (PEREIRA et al., 2020),

\footnotetext{
8 Para além de discutirmos as formas como o "risco social" é produzido no campo da linguagem, é importante interrogarmos o modo como a cristalização de determinadas ideias na superfície discursiva torna ainda mais obsoleto o histórico processo de exploração nas relações capital-trabalho. Ao fazer uso do termo "vulnerável" e seus derivados, seja adjetivado ou na forma de substantivo, o discurso que se opera nos documentos oficiais produz a ideia de que isso seja um estado quase que natural dos sujeitos e não algo construído socialmente pela extração da força de trabalho de quem só pode contar com isso para sobreviver. Isto é, as condições sociais, políticas e econômicas que produziram esse processo de estratificação subalternizada restam ainda mais apagadas em nome de uma cultura da solidariedade cínica, do assistencialismo e da manutenção da hegemonia burguesa.

${ }^{9}$ Estão sendo investidos $\mathrm{R} \$ 18.000 .000,00$ na impressão e compra de materiais que serão entregues. A quem possa interessar, no canal do Fundo Nacional de Desenvolvimento da Educação (FNDE), encontra-se disponível a reprodução da Audiência Pública realizada para processo licitatório dos Kits para Literacia Familiar do Programa Conta Pra Mim. Nessa audiência, cada material é apresentado, bem como as quantidades a serem adquiridas e breves ilustrações do que será distribuído. Disponível em: https://www.youtube.com/watch?v=Ylnu5mD-ZQE. Acesso em: 25 set. 2020.
} 
preparando-os, a curto prazo, para propostas curriculares aos moldes do Escola sem Partido ${ }^{10}$; a longo prazo, prepara-se para a aceitação dócil e benevolente das expropriações secundárias (retirada de direitos, expropriação de contrato de trabalho, aposentadoria). Preparar as crianças desde agora para as condições de desempregado, subempregado ou de desamparo pelos serviços públicos essenciais, por exemplo, é também um modo de dominação de classes pensado a longo prazo. Se Duarte (2008) afirmava que aos professores delegava-se a tarefa de lidar com a realidade social imediata com tal servidão, laborando melhor por competências que a moral do trabalho exige dos indivíduos, aos moldes do homeschooling, agora essa tarefa vem antecipada pelas orientações e materiais enviados às famílias. A psendocoerência de um mundo injusto marcado pela exploração do trabalho que se quer incutir também nas crianças (CHAVES; EVANGELISTA, 2020) logra o bem-recebido apoio de um facilitador potente: o livro infantil grosseiramente modificado e entregue em casa!

Dessa forma, se achávamos, como comentamos nas palavras introdutórias, que o engodo que alimenta a confusão entre fundamentos moralizantes e uma experiência estética com a leitura literária na infância (GHIGGI; CHAVES; SCHNEIDER, 2018) era tarefa superada, miseravelmente, práticas autoritárias e reducionistas de moralização da conduta promovidas por este governo nos obrigam a dar alguns passos atrás.

Em se tratando da leitura, de modo mais aberto e a tomando como uma prática, Paiva (2014) aponta que, no contexto brasileiro, os atos esporádicos de promoção, fomento e acesso à leitura são praticados pelo Ministério da Educação desde a década de 1930, quando da sua criação. Ainda que com pouco relevo, nos anos 1980, a preocupação com uma certa ideia de "formação de leitores" adentrou a agenda das políticas públicas nacionais. No entanto, além de serem pouco figurativas entre projetos mais globais e hegemônicos, foram também prejudicadas pelas rupturas de alguns fluxos das políticas públicas mais enfocadas no momento. Referindo-se às Políticas Públicas de Leitura Literária, a autora destacou algumas dessas ações, quais sejam:

\footnotetext{
${ }^{10}$ Projeto de Lei n. 7180/2014, popularmente conhecido como Lei da mordaça, que teve seu arquivamento em dezembro de 2018, voltando a ser debatido em 2019. Em agosto deste ano, o Supremo Tribunal Federal considerou inconstitucional semelhante lei no estado de Alagoas, nomeada "Escola Livre". O texto versava sobre a proibição de práticas de "doutrinação política e ideológica" na escola e defendia a garantia de uma "educação moral livre".
} 
O Programa Nacional Sala de Leitura - PNSL (1984-1987); o Proler, criado pela Fundação Biblioteca Nacional, do Ministério da Cultura; o Pró-leitura na formação do professor (1992 -1996) e o Programa Nacional Biblioteca do Professor (1994). Em 1997, criou-se o Programa Nacional Biblioteca da Escola (PNBE), [...] programa [...] executado pelo Fundo Nacional de Desenvolvimento da Educação (FNDE), em parceria com a Secretaria de Educação Básica do MEC e [destinado] à composição e distribuição de acervos de literatura para as bibliotecas das escolas públicas brasileiras que atendem a todos os segmentos da Educação Básica (PAIVA, 2014, on-line).

Complementando de certa maneira a referida listagem, e demarcando a formação de professores, é importante citar outros três programas federais de formação continuada de profissionais da educação básica: o Programa de Formação de Professores Alfabetizadores (Profa), que vigorou entre os anos de 2001 e 2002; o Pró-Letramento (2005, 2008 e 2010 a 2012) e o Pacto Nacional pela Alfabetização na Idade Certa - PNAIC (2012 a 2018). Mesmo que o trabalho com a literatura não seja o alvo central de cada um deles, esse aspecto não fica de fora em tais políticas, ganhando proeminência no PNAIC. Oscilam entre eles concepções de literatura como divertimento, deleite, prazer imediato ${ }^{11} \mathrm{ou}$, ainda, como meio de reflexão sobre a língua materna (RAMALHETE, 2019).

Ainda que o que se tenha hoje seja o retrocesso recrudescido que chega ao ponto de exaurir obras artísticas literárias, como dissemos, esse rol de ações ratifica que é aparente o ensejo de uma efetiva "democratização da leitura" que vinha hipoteticamente sendo praticada em outros governos. Assim, a cada novo programa proposto, nota-se uma atualização da tentativa de amortecimento das cisões entre as classes sociais para a manutenção mais harmônica possível da concentração de capitais - inclusive o das editoras. No entanto, é igualmente necessário discernir que essas tentativas possuem maior ou menor grau de intervenção na consciência social e cerceamento do pensar dos professores, da classe trabalhadora e de seus filhos.

\footnotetext{
${ }^{11}$ Esse fenômeno nos remete à análise feita por Walter Benjamin, citada por Catini (2013, p. 163), sobre os sentidos de uma cartilha da Escola Nova e seu distanciamento primeiro do objeto e depois da ciência: "Involuntariamente, mas de maneira tanto mais decisiva, essas palavras caracterizam com exatidão a insólita problemática que se tornou a marca de nossa formação. Por toda parte a mão livre dissociada começa a prevalecer sobre a pesada e vetusta. Mas não é fácil dizer quanto desta dissociação não é fraqueza, quanto dessa liberdade" não seria oportuna negligência.
} 
Ávila (2016), por exemplo, corrobora isso ao analisar a política de incentivo à leitura no âmbito federal, estadual e municipal — no município de Francisco BeltrãoPR — entre 2005 e 2015. A autora pondera sobre as práticas de professores com livros infantis que dissimulam os conflitos mais estruturantes da sociedade de classes e reproduzem ideologias hegemônicas, em um movimento que reforça uma suposta realidade harmônica e enfraquece ainda mais a base teórico-crítica do professor. A autora questiona o motivo de grandes empresas e o Estado desenvolverem projetos de leitura nas escolas e problematiza as teorias pedagógicas ou concepções de leitura que orientariam essas políticas. Ela ainda sugere a necessidade de haver proposições contraideológicas nos documentos orientadores que possam fomentar propostas críticas e emancipatórias, o que a nós parece pouco eficaz. O estudo sinaliza que as políticas de leitura, embora sejam apresentadas às classes populares com discursos salvacionistas, dissimulam interesses do capital e de uma pedagogia da hegemonia estatal e empresarial.

Esse brevíssimo apanhado nos coloca frente à urgência de debates sobre o lugar dos estudos da linguagem na formação de pedagogos; sobre os fundamentos filosóficos e psicológicos do trabalho com a literatura infantil; sobre os modos como ela tem sido manejada nas políticas educacionais, para citar somente três subcampos de pesquisa. Um dos tentáculos dessa discussão mais alargada é a dimensão estética da leitura literária infantil, por ser um caminho de acesso aos próprios sentimentos, para extrapolar fronteiras da conduta padronizada que favorece o protofascismo, para participar da cultura, atribuir sentidos ao vivenciado, desenvolver a atividade criadora, conciliar maneiras de se relacionar com o mundo e com as pessoas, enfim, formar-se de modo mais pleno possível como um sujeito do conhecimento histórico.

Antes de passarmos à próxima seção e seguirmos no caminho de pensar alguns dos fundamentos supramencionados, fazemos um esclarecimento sobre quem é esse sujeito-histórico. É Benjamin (1994c, p. 228, grifo nosso) quem nos ajuda a aparar essa aresta: "O sujeito do conhecimento histórico é a própria classe combatente e oprimida. Em Marx, ela aparece como a última classe escravizada, como a classe vingadora que consuma a tarefa de libertação em nome das gerações de derrotados". Sem termos isso como horizonte, corremos o risco de seguir privando esse sujeito "das suas melhores forças. A classe operária desaprendeu nessa escola tanto o ódio como o 
espírito do [verdadeiro] sacrifício. Porque um e outro se alimentam da imagem dos antepassados escravizados, e não dos descendentes liberados” (1994c, p. 229).

\section{A imaginação e a criatividade pela perspectiva vygotskyana}

Permeia toda a obra de Vygotsky a máxima de que o desenvolvimento das crianças está pautado nos modos de apropriação da cultura. Esse movimento envolve uma atividade da criança que demanda participação efetiva na cultura, de modo a fazer parte dela mesma maneiras sociais de compreender, sentir, pensar, comunicar e interagir com os demais (SMOLKA, 2009). Vygotsky foi um dos estudiosos que procurou uma alternativa no cerne do materialismo histórico para resolução do conflito entre as perspectivas mecanicista e idealista na área da psicologia. Seu pressuposto fundamental é de que as origens das formas superiores de comportamento consciente (memória, pensamento, etc.) precisam ser compreendidas com base nas relações sociais do homem, ser que age no mundo. $\mathrm{O}$ autor enfocou a reconstrução interna de operações externas do homem enquanto movimento dialético (BOCK; FURTADO; TEIXEIRA, 2008).

Vygotsky buscou um princípio que elucidasse a ideia de que a imaginação — tomada como atividade humana e não uma competência a priori — é sustentada pela experiência sensível e modificada pela ação do homem, pela tentativa de significar o existente pelos aspectos culturais (SMOLKA, 2009). Em Imaginação e criação na infância (2009), o autor destaca o caráter plástico da estrutura cognitiva que, ao mesmo tempo que modifica o vivido, conserva diversos dos seus aspectos. Além disso, o autor põe em xeque os significados mais comuns dados à concepção de imaginação, muito correntemente tomada como algo distante da realidade individual das pessoas ou, por vezes, como uma característica somente de alguns, individual e que pouco altera o plano social e político. Desconstituindo essa ideia, ele notou os desempenhos, as particularidades e as funções do ato de criar para a existência humana. As maneiras como a imaginação e a realidade se relacionam e o modo como a emoção influi a imaginação e como essa motiva as emoções. $\mathrm{O}$ autor ainda mostra que a imaginação, 
que tem na cultura e na linguagem suas determinações, vai sendo alterada pelos modos racionais de pensar, histórica e contextualmente modificados (SMOLKA, 2009).

A arte, como trabalho do pensamento emocional específico, "surge inicialmente como o mais forte instrumento na luta pela existência", declara Vygotsky em sua obra Psicologia da arte (2001, p. 310). Segundo o autor, ela tem sua origem em uma sensibilidade vital que não se esgota em si mesma. Por meio da catarse, ela reelabora e vivifica esses sentimentos. Nas palavras de Vygotsky (2001, p. 315), “[...] a refundição das emoções fora de nós realiza-se por força de um sentimento social que foi objetivado, levado para fora de nós, materializado e fixado nos objetos externos da arte, que se tornaram instrumentos da sociedade”. Mas, para isso, não há uma finalidade préestabelecida, a arte não conduz diretamente a nada. O que ela faz é da ordem do incitar “[...] tão somente uma necessidade imensa [...] de agir", de modo a alcançar vigores que subjazem intensamente em cada um. "A arte é antes uma organização do nosso comportamento [...], uma exigência que talvez nunca venha a concretizar-se, mas que nos leva a aspirar acima da nossa vida o que está por trás dela” (2001, p. 320). As relações entre essas sensações e uma forma complexa de atividade psíquica, a imaginação humana, dependem da conciliação de diferentes funções características. Nessa vereda, ela deve ser inteirada, sintetizada, materializada em uma palavra, uma obra, um artefato cultural, logrando forma, integrando-se, em um trânsito que vai da subjetividade à objetividade, à produção coletiva (SMOLKA, 2009, p. 30).

Em que pese a distinção sobre os fundamentos psicológicos entre os autores, as concepções de arte e imaginação propostas por Vygotsky têm confluência com o que Benjamin pensava sobre a função política da fantasia. Nesse sentido, acolhemos suas contribuições como base fundamental para a compreensão da função social e cultural que há no fenômeno criativo da leitura literária, pois, diferentemente do que uma área científica mais estrita denomina com o termo imaginação, a psicologia vygotskyana concebe tal atividade como criadora, fundamentada na competência de conciliação do cérebro. No uso menos rigoroso dos termos, a imaginação e a fantasia acabam sendo tratadas quase que como sinônimos - ainda que, diferentemente desta, aquela se refira a uma atividade psicológica - e são tomadas como algo que não faz parte da realidade, desse modo, não seria possível que tivesse acepção prática séria. Todavia, em confronto com essa vulgarização, é necessário que pensemos em um dos 
pilares mais estruturantes da teoria crítica no que compete ao aspecto contingencial da realidade e a sua apropriação da teoria marxiana: no modo como os fenômenos se apresentam para nós não estão contidos os modos como eles poderiam ser? Essa não é uma chave estruturante para a transformação radical da sociedade? Disso não depende - e a isso não responde - nossa atividade imaginativa?

De fato, a imaginação, estrutural para a atividade criadora, revela-se em todos os espaços da vida cultural, o que possibilita não somente a criação artística como inclusive a criação científica e a criação dita técnica. Realizar projetos e produzir o novo são atividades viabilizadas pela imaginação, que transcende o devaneio ou fantasia singular, apesar de abarcá-los. Essa é a natureza social de seu desenvolvimento. No âmbito das funções psicológicas complexas, ao mesmo tempo que consiste em uma atividade voluntária, é também elaboração da consciência. Logo, é inconteste sua função estrutural no encaminhamento das ações, tanto sociais quanto individuais.

Lastreada nessas considerações, é possível compreender que a imaginação criativa consiste também na competência de conciliação de diversas maneiras de se relacionar com o mundo e com as pessoas. Diferentemente de uma aceitação ou de uma postura negligente, comportamentos a que mais nos opomos aqui, essa conciliação faz parte do movimento de percepção e reelaboração da complexidade dos fenômenos sociais com que as crianças se deparam. Isso demanda que sejam coligadas imagens subjetivas e saberes objetivos, de modo que esses não podem ser compreendidos fechados em si mesmos. Tal associação permite que seja possível que a imaginação seja materializada, do mesmo modo que a materialização se torne pensamento e devir-sensivel.

Existe, dessa forma, um possível — ainda que não garantido nem comprovável empiricamente a curto prazo - pós-efeito cognitivo da leitura de literatura infantil, quando essa permite e estimula a reelaboração da realidade vivida pelas crianças. Considerando sua estreita relação com a compreensão de conceitos, por exemplo, a experiência com a literatura auxilia a captar o que há de universal em cada particularidade e a agrupar fatos que, de antemão, eram para ela inteiramente dispersos, haja vista o modo sincrético de pensar das crianças.

O trabalho criativo é sempre colaborativo e social e age coligando sensibilidade, materialidade e pensamento. É esse trabalho de construção humana e 
de participação social na cultura que nos faz perceber que a criação não suscita do vazio. Os sentidos dados à leitura literária infantil configuram, desse modo, um espaço no qual são incorporadas pelas crianças as impressões que elas têm advindas das práticas e do exercício de funções e conjunturas sociais (SMOLKA, 2009); colaboram com a "reelaboração criativa de impressões vivenciadas". É possível que seja o temor a essa reelaboração criativa que tenha feito com que algumas perversidades tenham sido eliminadas dos livros em Conta pra Mim. Talvez a disposição de lobos e bruxas de comer crianças ajudem "[...] os pequenos a administrar, no imaginário, o desejo canibal de tantos adultos" (COLASANTI, 2020, não p).

Ainda se referindo às obras artísticas, Vygotsky manifesta que o prazer que sua criação proporciona alcança o "[...] ponto culminante quando ficamos quase sufocados de tensão, com o cabelo em pé de medo, quando as lágrimas rolam involuntariamente de compaixão e simpatia. [...] São relações que evitamos na vida e estranhamente procuramos na arte" (2001, p. 83). Isso não combina nem um pouco com textos leves, com exemplos a serem seguidos ou com as ditas histórias sadias, pois elas sonegam a insubstituível inadaptação, que provoca as necessidades e desejos, sem os quais nada se cria e pouco se desconfia. E é também nesse aspecto, na condição mais íntima e sensível da participação humana, que laboram os conceitos abordados na seguinte seção.

\section{Dos conceitos de mímese e imagem dialética}

Em uma leitura um tanto mais incrédula das concepções propostas por Walter Benjamin, Giorgio Agamben (2008) afirmou que tudo aquilo a ser falado sobre a experiência deveria partir da inexorável constatação de que ela não mais consiste em algo que ainda fosse possível realizar. De modo que, da mesma maneira como o homem vem sendo privado da sua biografia há algum tempo, seria também desapropriado de sua experiência. O autor complementou indicando a probabilidade de que tal impossibilidade - de fazer e transmitir experiências - seria uma de suas poucas certezas (AGAMBEN, 2008).

Ainda que haja motivos de sobra para acatar o pessimismo e o apagamento de parte das contradições próprias da materialidade da vida trazidos por Agamben, a 
conjuntura exposta na segunda seção demanda, de modo tão mais urgente, um deslocamento nosso sem descanso e a procura pelo que resta de possibilidades. Georges Didi-Huberman propõe semelhante alerta ao fazer referência ao posicionamento fatalista de Pasolini, que atestou o desaparecimento total dos vagalumes. "Aprendo que existem ainda, vivas, espalhadas pelo mundo, duas mil espécies conhecidas desses pequenos bichinhos [...]. Como observava Pasolini, a poluição das águas no campo faz com que morram, a poluição do ar na cidade também” (2011, p. 49). Entretanto, isso não pode conduzir a comportamentos suicidas. O autor complementa a analogia que estrutura parte de sua obra exemplificando como ocorre quando larvas de vaga-lumes sobem nos postes elétricos, onde ainda haveria luz, e se transformam em pupas. Elas ficam “[...] perigosamente expostas aos predadores diurnos e ao sol que as resseca até a morte. É preciso saber que, apesar de tudo, os vaga-lumes formaram em outros lugares suas belas comunidades luminosas" (DIDIHUBERMAN, 2011, p. 50).

É possível pensar que a ideia de sobrevivência, proposta por Didi-Huberman, enquanto condições antropológicas de resistência ao poder centralizador do fascismo, nos ajuda a melhor interpretar a continuação que ele dá ao conceito benjaminiano de imagem dialética ${ }^{12}$. Esse conceito reforça a urgência de oposição às ações ultraconservadoras ressuscitadas por este governo em relação à obra de arte literária, visto que isso demonstra o quanto ela pode desde a infância. A utilização do termo sobrevivência encontra-se ancorada na perspectiva da experiência benjaminiana, haja vista sua não eliminação de todas as condições de existência e de realização da atividade humana por vias da criação. Entretanto, bem como um aviso de incêndio (LÖWY, 2005), faz alertar que está em vias de extinção.

Didi-Huberman propõe uma leitura da teoria benjaminiana que está de acordo com a constatação de que o futuro inevitável da humanidade é o mundo administrado e o progresso vem nos conduzindo a uma sociedade adaptada a isso. Benjamin não milita pela revolução no sentido apocalíptico de sua apreensão. Seu otimismo prático, que ilumina a necessária organização do pessimismo, condiz com um desapego a expectativas longínquas e abstratas. Isso faz com que, até mesmo ao falar da obra de

\footnotetext{
${ }^{12}$ Didi-Huberman o reatualiza partir da própria perspectiva benjaminiana e chega na ideia de imagem crítica, haja vista a dimensão histórico-crítica do conceito benjaminiano.
} 
arte em sua reprodutibilidade técnica (BENJAMIN, 1994a), ainda que a sociedade administrada seja campo fértil para o fascismo, constate-se esse otimismo da ação, por reconhecer a função subversiva que a imagem e o cinema podem exercer, que expõem acerca do que faz̧er com essa era, apesar de.

É nessa adversativa que reside a potencialidade das imagens dialéticas para o autor e para nosso objeto de debate, por serem capazes de superar dicotomias entre conhecimento e criação, entre o pensamento, a imaginação, a abstração e a materialidade da vida. No entanto, isso não ocorre sob uma orientação pseudocoerente, ordenada pelo mito do progresso, que quer fazer de conta que resolve no plano ideológico antagonismos que não serão resolvidos pela alteração das forças de produção existentes. Nas palavras de Benjamin:

Não é que o passado lança sua luz sobre o presente ou que o presente lança luz sobre o passado; mas a imagem é aquilo em que o ocorrido encontra o agora num lampejo, formando uma constelação. Em outras palavras: a imagem é a dialética na imobilidade. Pois, enquanto a relação do presente com o passado é puramente temporal, a do ocorrido com o agora é dialética - não de natureza temporal, mas imagética. Somente as imagens dialéticas são autenticamente históricas, isto é, imagens não arcaicas. A imagem lida, quer dizer (BENJAMIN, 2009, p. 505).

Evidentemente, nos termos do que se propõe aqui, as imagens dialéticas não se referem unicamente - todavia, inclusive — às ilustrações dos livros infantis, mas à imagem enquanto mímesis, imitação e expressão. Isto é, refere-se aqui à potencialidade que uma obra, carregada dessas imagens, pode acarretar. Atuando por meio do choque anacrônico temporal que carregam consigo, as imagens são capazes de "[...] mostrar justamente o motor dialético da criação como conhecimento e do conhecimento como criação" (DIDI-HUBERMAN, 1998, p. 179). A imagem dialética diz respeito a uma maneira distinta de conhecer as coisas mundanas, pois ela provoca a tensão temporal. Desse modo, a leitura literária — quando pensada como espaço privilegiado para a trânsito dessas imagens - considera antes o potencial que há na relação inédita das obras com aquilo que é intuído e compreendido nas práticas singulares e coletivas do que qualquer possibilidade de conteúdo moral ou informativo que elas possam conter.

Nesse sentido, considerar a dialeticidade da leitura literária infantil, tanto quanto de uma imagem dialética, pressupõe, como propõem os autores, abrir os olhos 
para experimentar o que não é possível ver com toda a evidência, de modo que essa experiência nunca é de ganho, de pertencimento, de posse, e sim de perda. "A modalidade do visível torna-se inelutável — ou seja, voltada a uma questão do ser — [...] quando ver é perder. Tudo está aî” (DIDI-HUBERMAN, 1998, p. 34), o que supõe uma coexistência viva e em movimento. As imagens dialéticas são imagens autênticas pelo seu aspecto de crise, como uma transição abrupta, que manifesta o que de efetivamente novo pode ser pensado. Quando do encontro entre o vivido e a palavra, revelam-se também os limites a que se pode chegar (autocrítica), o que nos coloca em dúvida, ainda que nem sempre por nós explicitada, sobre nossos modos de compreendê-las. As imagens autênticas nos obrigam a olhá-las verdadeiramente e eis aí seu caráter subversivo.

Benjamin, certa vez, respondeu a uma carta a Theodor W. Adorno dizendo que o cotejo entre a imagem dialética e a arcaica continuava a circunscrever um dos empenhos filosóficos determinantes das Passagens (2009). Nessa extensa obra (provavelmente nascida para ser inacabada), Benjamin apresenta a sincronia, que é determinante temporalmente para tal oposição, da seguinte forma:

O índice histórico das imagens diz, pois, não apenas que elas pertencem a uma determinada época, mas, sobretudo, que elas só se tornam legíveis numa determinada época. E atingir essa legibilidade constitui um determinado ponto crítico específico do movimento em seu interior. Todo o presente é determinado por aquelas imagens que lhe são sincrônicas: cada agora é o agora de uma determinada cognoscibilidade. Nele, a verdade está carregada de tempo até o ponto de explodir (BENJAMIN, 2009, p. 504-505).

Essa sincronia, que constitui a constelação e que, como dito, realiza-se por meio de um salto entre o ocorrido e o agora, diferentemente de uma ordenação linear, funciona como espaços de suspensão e produz um campo de tensão que labora por meio da mímese, pela produção de semelhanças, enquanto capacidade humana.

Fala-se em capacidade humana, uma vez que o conceito de mímese que interessa aqui se refere ao exercício de funções em praticamente todos os aspectos humanos da ação, do falar, do pensar e da imaginação, inclusive, como é mais correntemente referida. Pensando dessa forma, ela é uma condição indispensável ao agir no mundo e à vida social. Isto é, diferentemente daquele sentido mais limitado que foi dado às definições “[...] de mímese que constroem uma oposição entre mímese e a auto- 
imponência do homem moderno (BLUMENBERG, 1981) ou veem a atuação de mímese meramente na diferenciação das representações literárias da realidade (AUERBACH, 1982)" (GEBAUER; WULF, 2004, p. 21), ela passa a ser concebida como faculdade antropológica fundamental (CHAVES, 2017), em sentido um tanto próximo do que Vygotsky acolhe a capacidade humana criativa. Isso somente é viável se o termo for empregado em um sentido que não se satisfaz com seu uso platônico, que tinha "[...] como designação do reproduzir, do copiar, do imitar objetos reais por meio da não-realidade" (GEBAUER; WULF, 2004, p. 21).

Essa fundamentação antropológica da mimesis nos conduz a um modo de operar das imagens dialéticas que se torna determinante para a forma de compreender as relações estéticas da leitura literária infantil. Mais que uma parte da semiótica, "[...] o conceito de mimese encontrou ressonância na teoria do homem" (GEBAUER; WULF, 2004, p. 25) e faz parte dele a criação "de artefatos, em que são sublinhados particularmente os aspectos corporais, perceptivos e emocionais, assim como o temporal. Sob o ponto de vista da mimese, busca-se uma outra forma de ação humana que tenha como ponto central a práxis de ação" (p. 25, grifo nosso).

Isso tudo nos ajuda a clarificar a distinção que Benjamin estabelece, no campo da crítica à estetização da política, entre metáforas e imagens. Interroga ele: “Onde estão os pressupostos da revolução? $\mathrm{Na}$ transformação das opiniões ou na transformação das relações externas?” (1994b, p. 33). É Pierre Naville quem fornece as bases para que Benjamin afirme que "[...] é na política que a metáfora e a imagem se diferenciam da forma mais rigorosa e mais irreconciliável, [...] que não admite qualquer camuflagem" (1994b, p. 33-34).

Essa estreita relação brevemente articulada nesta seção indica para nós que a chamada guerra cultural não pode ser tomada como acessória na disputa pela hegemonia política acirrada neste momento em que nos encontramos. Os fenômenos sociais existem independentemente de nós, mas é na linguagem que a gente age e dá sentidos para eles, para as direções em conflito e para o domínio que vem sendo praticado. Se levamos isso a sério, mais facilmente estreitamos as relações entre o que é previsto pelas políticas públicas educacionais no que compete à formação da sensibilidade e a projeção econômica que há nessas ações aparentemente acessórias. 
A leitura literária foi pouco atendida em outras políticas públicas e é mais um alvo deste governo moralizante, além de outros cerceamentos, porque ela funciona por imagens, que conglomeram a experiência vivida dos leitores em formação com o "agora da cognoscibilidade, e carrega no mais alto grau a marca do momento crítico, perigoso, subjacente a toda leitura" (BENJAMIN, 2009, p. 505).

\section{Para início de conversa}

Antes da conclusão deste ensaio, tomamos conhecimento do breve escrito de Colasanti (2020, não p). Lembra ela que "quando o moralismo inventa suas próprias histórias, revela-se rasteiro e óbvio. Então recorre a histórias bem plantadas no imaginário universal, e as adapta. Mas ao adaptá-las as desconstrói. E ao abrir a pata só encontra um punhado de moscas"! Como o capital trabalha a longo prazo, é a esse vazio que a imaginação dos filhos da classe trabalhadora tem sido jogada, o que dificulta a descoberta "no espaço da ação política o espaço completo da imagem” (BENJAMIN, 1994b, p. 34). Para que o processo de reprodução do capital encontre cada vez menos obstáculos, forças destrutivas permanecem sendo desencadeadas, seja dizimando a natureza, a sociabilidade, a natureza humana, a arte, a literatura.

Bem sabemos que as obras literárias podem suscitar transformações na consciência social das crianças e a leitura literária infantil, pensada por meio de suas imagens dialéticas, trabalha com outros modos de perceber e conhecer as conjunturas, pois age pela inadaptação que provoca as necessidades e desejos, e não pela tentativa de propor ideias conciliadoras, pragmáticas e utilitárias (ainda que isso eventualmente ocorra). Esse espaço de trânsito das imagens por excelência incita na criança a produção de sentidos também na dimensão social-subjetiva, que é "constituída e invadida pela apropriação de práticas, de signos, de aspectos culturais" (SMOLKA, 2009, p. 41), que são essencialmente ideológicos.

Para tanto, seja nos programas de formação continuada de professores, seja em propostas de distribuição de materiais, é urgente que, antes de tudo isso, reivindiquemos as condições de participação das crianças na produção de sentidos na prática da leitura literária, das quais depende o processo de criação. Isso não é 
meramente espontâneo, quanto mais garantido por algum programa de distribuição de "livros" que passaram por uma tosa grotesca. Queríamos dizer que a leitura literária encontra sua fecundidade quando não assume um aspecto nem teleologicamente fechado, nem indutivo, nem dedutivo, que não abre mão da crítica, mas nos parece que os últimos acontecimentos tornam até a reincidência desse alerta um tanto distante da realidade.

Na contramão disso, no último quadrante do século passado havia ainda uma pretensão (por vezes romantizada e idealista) das ciências humanas em tentar delimitar o que realmente a infância era. Uma leitura descompromissada do pós-estruturalismo fez acreditar que podia ser qualquer coisa ou conduzida para lado algum. Manifestações outras, inclusive literárias, demonstraram que talvez aquela impossibilidade ocorresse pelo fato de que a criança não se submete a qualquer autoridade ou poder. Ela quer participar do inventário do conhecimento humano pela produção de semelhanças, à sua maneira.

Em Retrato do artista quando coisa (1998), de Manoel de Barros, a incompletude humana, a necessidade de ser "outros" e de "renovar o homem usando borboletas" expande um tantão do que se comentou até aqui.

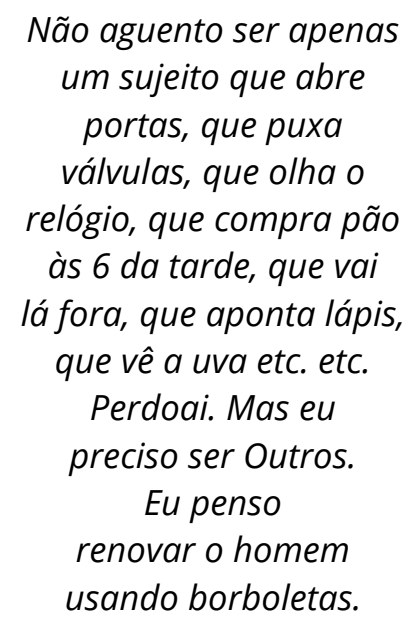

A literatura labora nesse encontro que não acata a medida do "saber" e menos ainda do "portar-se" que, por exemplo, uma certa política de reificação da fantasia lhe entrega em casa - que ensina a se conformar com abrir portas, puxar válvulas, olhar o relógio... Ela facilita que tomemos nosso lugar na função de elaborar concepções, para que não fiquemos somente no cumprimento de tarefas que nos são destinadas. 
Ela perpassa a presença alegórica da criança, sua postura de não se sentir condescendente com a moral do trabalho que quer promover a contenção política, por ser provocado pela necessidade de construção de um mundo de gente e não de coisas — sem renunciar às borboletas!

\section{Referências}

AGAMBEN, G. Infância e história: destruição da experiência e origem da história. Traduzida para o português por Henrique Burigo. Belo Horizonte: Editora UFMG, 2008.

AVILA, K. M. G. A ideologia do capital nas políticas públicas de incentivo à leitura: uma análise da política de incentivo à leitura no município de Francisco Beltrão-PR (2005-2015). Orientador: José Luiz Zanella. Dissertação (Mestrado em Educação) — Universidade Estadual do Oeste do Paraná, Francisco Beltrão, 2016.

BAKHTIN, M. Estética da criação verbal. São Paulo: Editora Martins Fontes, 2011.

BARROS, M. Retrato do artista quando coisa. Rio de Janeiro: Record, 1998.

BENJAMIN, W. A obra de arte na era de sua reprodutibilidade técnica. In: BENJAMIN, W. Obras escolbidas: Magia e Técnica, Arte e Política. São Paulo: Brasiliense, 1994a.

BENJAMIN, W. O Surrealismo. O último instantâneo da inteligência europeia. In: BENJAMIN, W. Obras escolbidas: Magia e Técnica, Arte e Política. São Paulo: Brasiliense, 1994b.

BENJAMIN, W. Sobre o conceito de história. In: BENJAMIN, W. Obras escolbidas: Magia e Técnica, Arte e Política. São Paulo: Brasiliense, 1994c.

BENJAMIN, W. Reflexões: sobre a criança, o brinquedo e o brincar, a educação. São Paulo: Duas Cidades; Ed. 34, 2002.

BENJAMIN, W. Passagens. Belo Horizonte: Editora UFMG; São Paulo: Imprensa oficial do estado de São Paulo, 2009.

BOCK, A. M. B.; FURTADO, O.; TEIXEIRA, M. L. T. Psicologias: uma introdução ao estudo da psicologia. São Paulo: Saraiva, 2008.

BRASIL. Decreto $n^{\circ}$ 9.765, de 11 de abril de 2019. Institui a Política Nacional de Alfabetização. Diário Oficial da União, Brasília, DF, 11 abril 2019a.

BRASIL. Ministério da Educação. Secretaria de Alfabetização. Conta pra Mim: Guia de Literacia Familiar. Brasília: MEC, Sealf, 2019b.

BRASIL. Ministério da Educação. Secretaria de Alfabetização. PNA: Política Nacional de Alfabetização. Brasília: MEC, Sealf, 2019c.

BRASIL. Ministério da Educação. Secretaria da Educação Básica. Base Nacional Comum Curricular. Brasília, 2018. 
CANDIDO, A. O direito à literatura. In: CANDIDO, A. Vários Escritos. 5. ed. Rio de Janeiro: Ouro sobre Azul; São Paulo: Duas Cidades, 2004.

CATINI, C. R. A escola como forma social: um estudo do modo de educar capitalista. Orientador: Carmem Sylvia Vidigal Moraes. Tese (Doutorado em Estado, Educação e Sociedade) Universidade de São Paulo, São Paulo, 2013.

CHAVES, P. M. Sobre a dimensão estética do conceito de leitura literária: perspectivas de uma Dialética Negativa. Orientador: Gomercindo Ghiggi. Tese (Doutorado em Educação) Universidade Federal de Pelotas, Pelotas, 2017.

CHAVES, P. M.; EVANGELISTA, O. Servidão benevolente até a morte? Contrapoder. Disponível em: https://contrapoder.net/colunas/servidao-benevolente-ate-a-morte/. Acesso em: 03 set. 2020.

COLASANTI, M. Não conta pra mim. Marina Colasanti. Out. 2020. Disponível em: https://www.marinacolasanti.com/2020/10/nao-conta-pra-mim.html?m=1. Acesso em: 8. out. 2020 .

DALVI, M. A. Literatura Infantil e democracia. In: GALVÃO, A. C.; ZAIDAN, J. C. S. M.; SALGUEIRO, W. (Orgs.). Foi golpe! O Brasil de 2016 em análise. Campinas, SP: Pontes Editores, 2019.

DECKER, A.; EVANGELISTA, O. Educação na lógica do Banco Mundial: formação para a Sociabilidade Capitalista. Roteiro, v. 44, n. 3, p. 1-24, 20 dez. 2019.

DIDI-HUBERMAN, G. O que vemos o, o que nos olha. São Paulo: Ed. 34, 1998.

DIDI-HUBERMAN, G. Sobrevivência dos vaga-lumes. Belo Horizonte: Editora UFMG, 2011.

DUARTE, N. Sociedade do Conbecimento ou Sociedade das Ilusões?: quatro ensaios crítico-dialéticos em filosofia da educação. Campinas, SP: Autores Associados, 2008.

FONTES, V. Gramsci, Estado e sociedade civil: anjos, demônios ou lutas de classes? Revista Outubro, n. 31, 2 sem. 2018.

GEBAUER, G.; WULF, C. Mimese na cultura: agir social, rituais e jogos, produções estéticas. São Paulo: Annablume, 2004.

GHIGGI, G.; CHAVES, P. M.; SCHNEIDER, D. C. A literatura infantil entre a experiência estética e a educação moral. Educação, v. 41, n. 3, p. 437-445, 30 dez. 2018.

LÖWY, M. Walter Benjamin: aviso de incêndio. Uma leitura das teses sobre o conceito de História. São Paulo: Boitempo, 2005.

MEIRELES, C. Problemas da literatura infantil. 3 ed. São Paulo: Summus, 1979.

MÉSZÁROS, I. Educação para além do Capital. São Paulo: Boitempo, 2008.

NEVES, R. M. C.; PICCININI, C. L. Crítica do imperialismo e da reforma curricular brasileira da educação básica: evidência histórica da impossibilidade da luta pela emancipação da classe trabalhadora desde a escola do estado. Germinal: Marxismo e Educação em Debate, Salvador, v. 10, n. 1, p. 184-206, mai. 2018. 
PAIVA, A. Políticas públicas de leitura literária. In: FRADE, I. C. A. S; VAL, M. G. C.; BREGUNCI, M. G. C. (Orgs.). Glossário Ceale. Belo Horizonte: UFMG, 2014.

PALO, M. J.; OLIVEIRA, M. R. D. Literatura Infantil: voz de criança. 4. ed. São Paulo: Ática, 2006.

PEREIRA, J. N. et al. "Pelo futuro agora": De frente para a tragédia na escola pública. Contrapoder. Disponível em: https://contrapoder.net/colunas/pelo-futuro-agora-de-frentepara-a-tragedia-na-escola-publica/. Acesso em: 20 set. 2020.

RAMALHETE, M. P. A leitura literária em programas governamentais de formação de professores alfabetizadores do início do século XXI (2001-2018): o tropeço, a trapaça e o deleite. Orientador: Cleonara Maria Shwartz. Tese (Doutorado em Educação) — Universidade Federal do Espírito Santo, Vitória, 2019.

SILVA, E. T. Leitura na escola e na biblioteca. 3. ed. Campinas: Papirus, 1991.

SMOLKA, A. L. B. Ana Luiza Smolka comenta Lev Vygotsky. VYGOTSKY, L. S. Imaginação e criação na infância. São Paulo: Ática, 2009.

STEN, S. C. Educação e Cinema: crítica à domesticação da memória em filmes de animação dos estúdios Disney. Orientador: Robson Loureiro. Tese (Doutorado em Educação) Universidade Federal do Espírito Santo. Vitória, 2020.

VALENTE, R. Conta outra. Quatro cinco um: a revista dos livros, 19 set. 2020. Disponível em: https://www.quatrocincoum.com.br/br/noticias/politicas-do-livro/conta-outra. Acesso em: 20 set. 2020.

VYGOTSKY, L. S. Psicologia da arte. São Paulo: Martins Fontes, 2001.

VYGOTSKY, L. S. Imaginação e criação na infância. São Paulo: Ática, 2009.

ZILBERMAN, R. A literatura infantil na escola. São Paulo: Global, 1985.

RECEBIDO: 05/05/2020

APROVADO: 26/11/2020
RECEIVED: 05/05/2020

APPROVED: $11 / 26 / 2020$
RECIBIDO: 05/05/2020

APROBADO: 26/11/2020 